\title{
The Possibility of Noticing the Cyclists Based on Reflective Effect of the Elements on the Bicycle Pedals
}

\author{
Sławomir Tarkowski, Aleksander Nieoczym², Jacek Caban³, Radovan Madleňák \\ 1 Department of Motor Vehicles, Faculty of Mechanical Engineering, Lublin University of Technology, \\ Nadbystrzycka 36, 20-618 Lublin, Poland \\ 2 Department of Machine Design and Mechatronics, Faculty of Mechanical Engineering, Lublin University of Technology, \\ Nadbystrzycka 36, 20-618 Lublin, Poland \\ ${ }_{3}^{3}$ Department of Agricultural, Forestry and Transport Machines, Faculty of Production Engineering, \\ University of Life Sciences in Lublin, Głęboka 28, 20-612 Lublin, Poland \\ ${ }^{4}$ Department of Communications, Faculty of Operation and Economics of Transport and Communications, \\ University of Zilina, Univerzitná 8215/1, 01026 Žilina, Slovakia \\ *Corresponding author, e-mail: radovan.madlenak@fpedas.uniza.sk
}

Received: 15 July 2019, Accepted: 19 November 2019, Published online: 30 March 2020

\begin{abstract}
The article presents the results of the research describing the changes of bicycle pedal angle relative to the ground, depending on the bicycle crank setting, and the impact of these parameters on detecting the reflective effect emitted by the reflective elements mounted on the bicycle pedals. The results of the road tests determining the cyclist detecting by a car driver, when bicycle is equipped only with bicycle pedals, reflective lights, illuminated with car's passing lights are also presented. The research described in this article has been carried out for the purpose of reviewing the causes of traffic accidents, occurring at night, in the areas not illuminated by the street lights, in which the cyclists using defective bicycles (according to the regulations) took part.
\end{abstract}

Keywords

traffic accidents, cyclist's visibility testing, car-bicycle collisions

\section{Introduction}

In recent years, the number of the cyclists riding on the roads has grown. In the field of no motorized transport we can see that the popularity of cycling and especially the bicycle as the means of individual transport instead of car (Gogola, 2018). It is a result of obvious advantages of this means of transport, that is, keeping fit and active spending of free time. Cycling, as an active mode of transportation, have well-established health benefits (Levulyte et al., 2016). The bikes also allow to move relatively fast, especially in urbanized areas and they are relatively cheap means of transport. Bicycle transport contributes to limiting the phenomenon of transport congestion (Bartuśka et al., 2015; Lizbetin and Bartuška, 2017), and particularly annoying noise in urban areas, which include the following research (Skrucany et al., 2017). The infrastructural and organizational investments help to develop bicycle transport, which is a part of the idea of the policy of sustainable development in many countries. However, safety of the cyclists is a significant problem reported in many publications (Hiselius and Svensson, 2017; Jurecki et al., 2017a; Jurecki et al., 2017b; Langford et al., 2015; Levulyte et al., 2016; Weber et al., 2014).

The cyclists are unprotected road users and their stream traffic often is often shared or crossed with the stream of motor vehicles. Another authors (Schepers and Wolt, 2012) indicate that about half of all single-bicycle crashes are related to the infrastructure: the cyclist rode off the road, or collided with an obstacle, the bicycle skidded due to a slippery road surface, or the rider was unable to stabilize the bicycle or stay on the bike because of an uneven road surface. When cyclists interact motorized road traffic there is a huge difference in speed and mass (Levulytė et al., 2016). Collisions between bicyclists or motor vehicles are a major problem in the countries that are becoming motorized, and in which there are high rates of cycling (Haleem et al., 2015). One of the problems that arise while driving is to notice obstacles on the road in this case noticing the cyclist. 
In accordance with the requirements specified in the regulations (Dz.U.2015.305, 2015), every vehicle riding on the public road (including bike), under the conditions of poor visibility, should be lit with the use of autonomous lighting and equipped with reflective elements. Same resources analyzed the interaction between the car drivers and the reflective elements of the traffic signs by eye-tracking technology (Madlenak and Hudak, 2016). The results show that during the daylight and especially night, the reflective elements are very important for the safety of road traffic (Madlenak et al., 2018). However, there are cases of collisions of unlit cyclists with the drivers at night. This problem refers mainly to rural areas and stretches of road that are not lit with the street lamps. The bikes often do not have their own sources of light and required reflective elements. The fact that the cyclists often do not have such accessories or they are damaged results from improper storage of the bike and attitude of the user, who ignores basic rules of traffic safety. The only reflective elements in such situations may be the elements on the bicycle pedals. These elements are durable and fail-safe. They may be "the last" element that helps to notice the cyclist at night. However, from formal point of view, it is not an obligatory element of bike accessories.

\section{Genesis of the problem}

The reflective elements used in the bikes have many micro prisms reflecting the light. According to the regulations (Dz.U.2015.305, 2015), reflective elements should be visible after lighting them from a minimum distance of $150 \mathrm{~m}$. Fulfilling these requirements is tested for the condition of the position of a reflective element at a perpendicular angle to the light source. Reflective effect given by reflective elements mounted on the bicycle pedals, while it is moving, is not kept during the full range of the crank rotation. Analysis of literature showed that the research on phenomena associated with reflecting the effect of the elements mounted on the bicycle pedals have not been carried out yet. The research described in this article have been carried out for the purpose of reviewing the causes of traffic accidents, occurring at night, in the areas not illuminated by the street lights, in which the cyclists using defective bicycles (according to the regulations) took part. Therefore, the results of the research are of practical importance and may be used in the process of reviewing traffic accidents.

\section{Methodology of research}

The research was divided into two stages. In the first stage, the authors examined the distances of noticing (of an approaching car by a driver) the reflective effect, emitted by the elements mounted on the bicycle pedals, after lighting with the use of dipped headlights. During this research, the cyclist rotated the crank of the bike ("pedaled"), which was placed on the so-called training simulator. It allowed to simulate riding with the bike remaining at the same place. During this stage, the impact of pollution of the reflective elements on the noticing distance was considered. In the second stage, the authors examined the impact of momentary position of a crank and pedal on the emission of reflective effect - after lighting with the use of car dipped headlights from a distance of $25 \mathrm{~m}$. In this case, the bike was also placed on "training simulator". The following variables were considered during both stages: height of a bike saddle and location of the foot on the pedal. The measurements were taken with the use of the bike without reflective elements - except for the elements on the bicycle pedals. It was lit with the use of car dipped headlights from the front and from behind. The vehicle used in the research was equipped with the headlights, in which halogen bulbs were the source of light. The distribution of the patches of the dipped headlights of this vehicle (Opel Astra) was presented on Fig. 1. The presence of the bike on the road (in a specific place) was something that the driver expected, therefore, the effect of surprise of the driver was not considered, which would affect the results of specific value of noticing distance. Technical state of the headlights and sources of light in the car was good. Therefore, obtained results are not underestimated due to potential faults limiting effective range of lighting the road by the dipped headlights of the vehicle (the impact of such faults was described in (Tarkowski et al., 2017).

During the research, the cyclist was taking various positions while "pedaling". They resulted from the height of a saddle and location of the foot on the bicycle pedals. Depending on position during crank rotation, location of a plane of the reflective element was changing. Foot may also obstruct reflective element, which may have impact on the possibility of noticing the reflective effect by an observer.

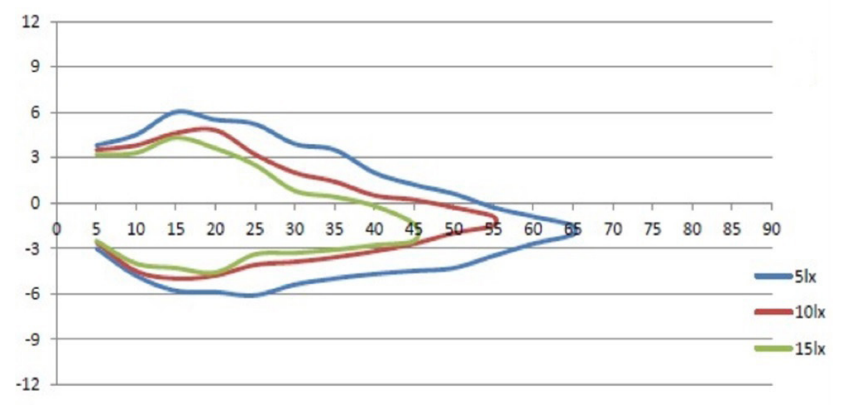

Fig. 1 The distribution of the patches of the dipped headlights of Opel car equipped with H7 bulbs (Tarkowski, 2017) 
The positions of a cyclist were marked as U1-U4. In the setting defined as U1, it was assumed that in the maximal, bottom position of a crank, angle between axis of femoral and calf bone of the cyclist ("angle in the knee") was higher than 170 degrees, and front part of the foot was in contact with the pedal. Such setting is more ergonomic and allows to optimally use the power of muscles (height of a saddle "correct", foot "correctly"). In the setting defined as U2, it was assumed that in the maximal, bottom position of a crank, "angle in the knee" of a cyclist was higher than 170 degrees, and the heel was in contact with the pedal (height of a saddle "correct", foot "incorrectly"). In the setting defined as U3, it was assumed that in the maximal, bottom position of a crank, "angle in the knee" of a cyclist was less than 170 degrees, and front part of the foot was in contact with the pedal (height of a saddle "incorrect", foot "correctly"). In the setting defined as U4, it was assumed that in the maximal, bottom position of a crank, "angle in the knee" of a cyclist was less than 170 degrees, and the heel was in contact with the pedal (height of a saddle "incorrect", foot "incorrectly").

In the second stage of the research, momentary position of a crank and changes of location of a plane of the bicycle pedal while "pedaling" were determined with the use of mounted measuring discs (Fig. 2). The course of the test was recorded with the use of two synchronized cameras: one camera monitored the position of a crank and the other camera recorded reflecting reflective effect of the element lit with the use of dipped headlights from a distance of $25 \mathrm{~m}$. At this distance, the reflective element at its lowest position (about $25 \mathrm{~cm}$ above base level) was located above focused stream of light beam of the dipped headlights. At its upper position, the reflective element was located about $55 \mathrm{~cm}$ above base level. The measurement station corresponded to road situation, in which car and bike were on the road $4.5 \mathrm{~m}$ wide, longitudinal axis of the car coincided with axis of the road, and the cyclist was $0.7 \mathrm{~m}$ from the edge of the roadway (Fig. 3).

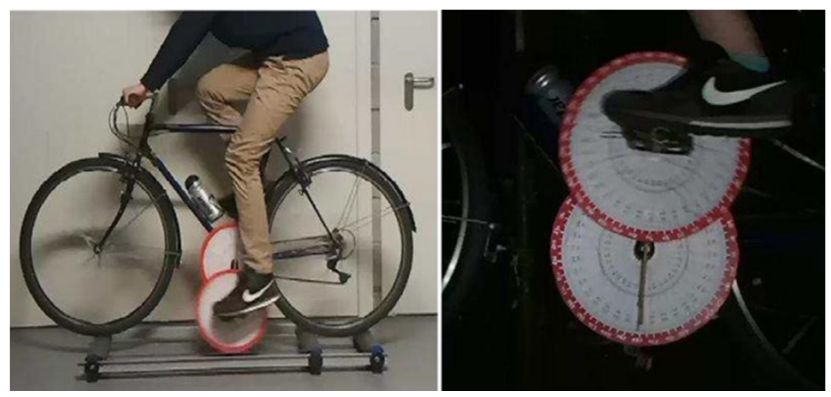

Fig. 2 The bike on the roller post and measuring discs

\section{Results}

The results of distance of noticing reflective effect from a place of the driver $\left(\mathrm{S}_{\mathrm{z}}\right)$ were presented in Table 1 . The distances of noticing "clean" and "smudged" reflective elements lit from behind (marked as $\mathrm{S}_{\mathrm{zt} \mathrm{c}}$ and $\mathrm{S}_{\mathrm{zt} \mathrm{z}}$ ) and "clean" and "smudged" lit from the front (marked as $\mathrm{S}_{\mathrm{zp}_{-} \mathrm{c}}$ and $\mathrm{S}_{\mathrm{zp}_{-} \mathrm{z}}$ ) were considered. The state of cleanliness of reflective elements used during the research was presented on Fig. 4. The noticing distances are presented in Table 1.

In the event of lighting of a cyclist at the position U1 (saddle "good", foot "good") from the front and „clean" reflected lights, the driver noticed the reflective effect from a distance of $172 \mathrm{~m}$.

It was the highest value from among all examined cyclist positions. At cyclist's position $\mathrm{U} 2$ and $\mathrm{U} 3$, in which one of the parameters of the cyclist position was "good",
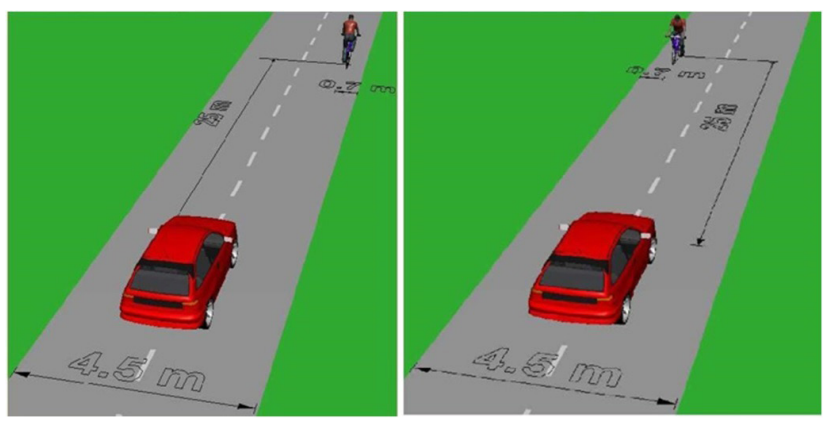

Fig. 3 The way of taking measurements
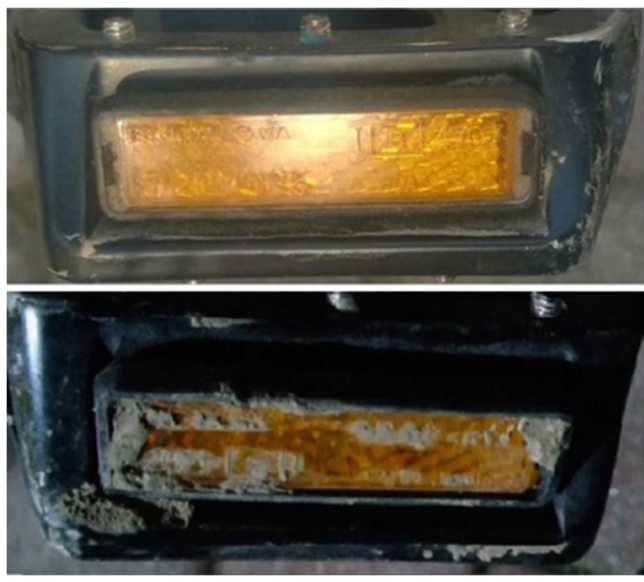

Fig. 4 The state of cleanliness of the reflective elements used during the research

Table 1 The distances of noticing reflective effect by a driver

\begin{tabular}{lcccc}
\hline \multirow{2}{*}{$\begin{array}{l}\text { Cyclist's } \\
\text { position }\end{array}$} & \multicolumn{2}{c}{ Lightning from behind } & \multicolumn{2}{c}{ Lightning from the front } \\
\cline { 2 - 5 } & $\mathrm{S}_{\mathrm{zt} \mathrm{c}}[\mathrm{m}]$ & $\mathrm{S}_{\mathrm{zt} \mathrm{z}}[\mathrm{m}]$ & $\mathrm{S}_{\mathrm{zp} \mathrm{c}}[\mathrm{m}]$ & $\mathrm{S}_{\mathrm{zp} \mathrm{z}}[\mathrm{m}]$ \\
\hline $\mathrm{U} 1$ & 161 & 95 & 172 & 113 \\
$\mathrm{U} 2$ & 155 & 93 & 168 & 109 \\
$\mathrm{U} 3$ & 156 & 91 & 165 & 107 \\
$\mathrm{U} 4$ & 137 & 77 & 145 & 95 \\
\hline
\end{tabular}


noticing distances were comparable and a little bit lower than maximal value determined with lighting from the front. The lowest value of the distance of noticing the reflective effect emitted by the reflective elements on the bicycle pedals lit from the front was observed for the cyclist position $\mathrm{U} 4$, in which saddle was too low and foot on the pedal was backed by the heel. The measured value of noticing distance was $145 \mathrm{~m}$. When the reflective element was dirty, measured noticing distances were lower in comparison with "clean" element by about 50-60 meters. In this case, the impact of the position of a cyclist on the bike on noticing distance was the same as the one determined for "clean" element, that is, the highest range for U1 setting, and the lowest for U4 setting. For the settings $\mathrm{U} 2$ and $\mathrm{U} 3$, noticing distances were similar and a little bit lower in comparison with U1 setting.

For the scenario, in which the cyclist was lit "from behind", similar relations of distance of noticing the reflective effect from the position of a cyclist on the bike and cleanliness of this element were observed. In this scenario, all measured noticing distances were lower by about 10-20 $\mathrm{m}$ in comparison with scenario, in which cyclist was lit "from the front". Observed regularity - connected with lowered distance of noticing reflective effect of the bike lit "from behind" is unexpected due to location of the cyclist on the measurement site towards asymmetric smear of the dipped headlights. In this context, the conclusion can be formulated that refers to the impact of "hanging" foot on the pedal on noticing distance.

The relation between reflecting reflective effect and momentary position of a crank, location of a plane of the bicycle pedal towards a plane of the ground and position of the cyclist were shown on the Figs. 5 and 6.

The range of crank rotation, in which reflective effect was intense and clearly noticeable in the dipped headlights from a distance of $25 \mathrm{~m}$ was marked with yellow color. The range of crank rotation, in which reflective effect was noticeable, but its intensity was lower in comparison with "intense and clearly noticeable" was marked with green color. The range of crank rotation, in which reflective effect was invisible for the observer sitting in a place of a driver in the car was marked with red color.

While lighting the bike from behind with the use of the dipped headlights, the following regularities have been observed that refer to the possibility of noticing the reflective effect by the driver:

- at position U1 taken by a cyclist (height of a saddle "correct", foot "correctly"), reflective effect given by
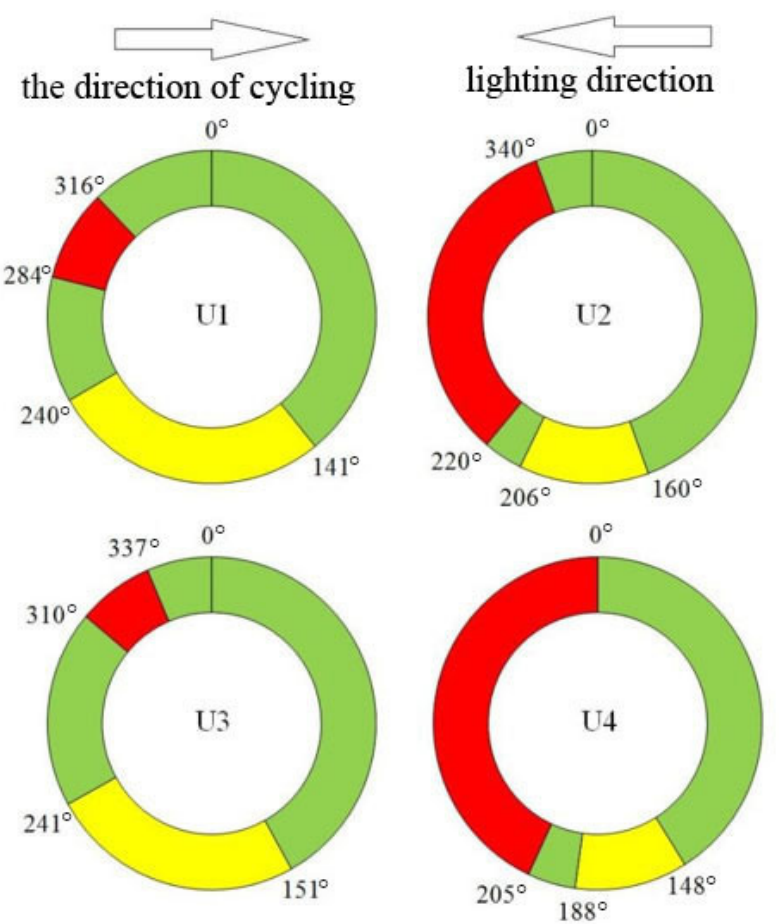

Fig. 5 Reflecting reflective effect depending on momentary position of a crank while lighting the bike from the front
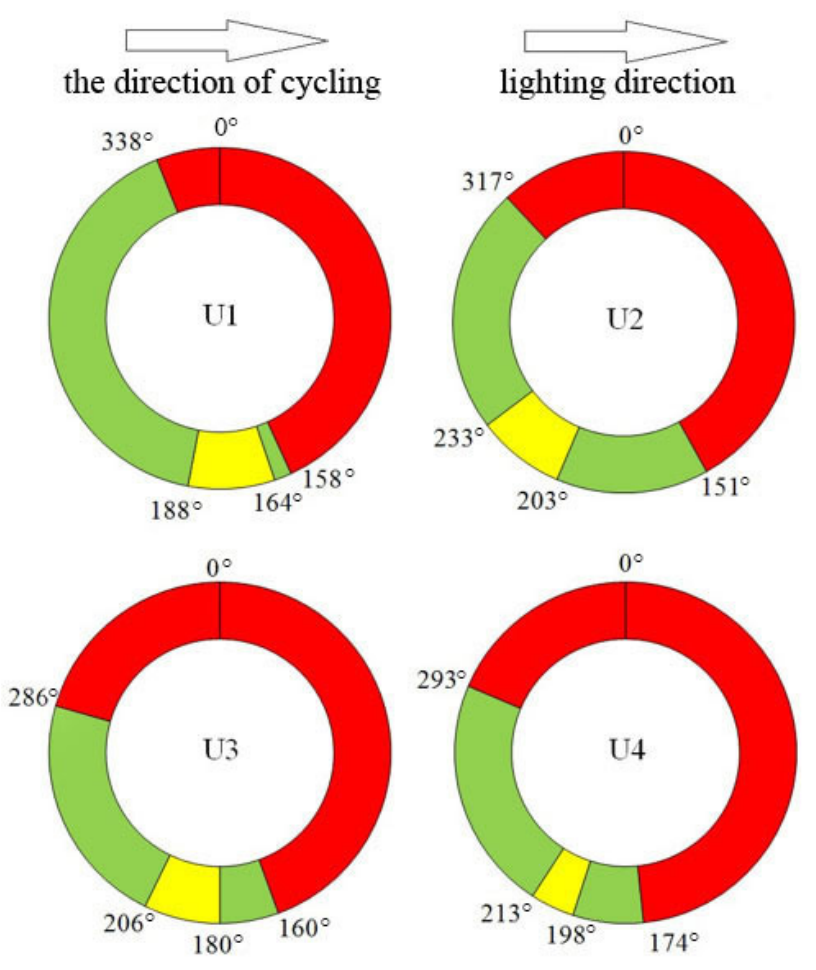

Fig. 6 Reflecting reflective effect depending on momentary position of a crank while lighting the bike from behind

the element mounted on the bicycle pedal - on the one side of a bike - observed within the range of $91 \%$ of full crank rotation; more powerful reflective effect 
was emitted within the range of $28 \%$ of full crank rotation, which corresponded to its angular position within the range of $141^{\circ}-240^{\circ}$ of rotation (assuming $0^{\circ}$ in the highest position of a pedal and direction of rotation ensuring the drive),

- at position U2 taken by a cyclist (height of a saddle "correct", foot "incorrectly"), reflective effect given by the element mounted on the bicycle pedal - on the one side of a bike - observed within the range of $67 \%$ of full crank rotation; more powerful reflective effect was emitted within the range of $13 \%$ of full crank rotation, which corresponded to its angular position within the range of $160^{\circ}-206^{\circ}$ of rotation,

- at position U3 taken by a cyclist (height of a saddle "incorrect", foot "correctly"), reflective effect given by the element mounted on the bicycle pedal - on the one side of a bike - observed within the range of $93 \%$ of full crank rotation; more powerful reflective effect was emitted within the range of $25 \%$ of full crank rotation, which corresponded to its angular position within the range of $151^{\circ}-241^{\circ}$ of rotation,

- at position U4 taken by a cyclist (height of a saddle "incorrect", foot "incorrectly"), reflective effect given by the element mounted on the bicycle pedal on the one side of a bike - observed within the range of $57 \%$ of full crank rotation; more powerful reflective effect was emitted within the range of $11 \%$ of full crank rotation, which corresponded to its angular position within the range of $148^{\circ}-188^{\circ}$ of rotation.

While lighting the bike from behind with the use of the dipped headlights, the following regularities have been observed that refer to the possibility of noticing the reflective effect by the driver:

- at position U1 taken by a cyclist (height of a saddle "correct", foot "correctly"), reflective effect given by the element mounted on the bicycle pedal - on the one side of a bike - observed within the range of $50 \%$ of full crank rotation; more powerful reflective effect was emitted within the range of $7 \%$ of full crank rotation, which corresponded to its angular position within the range of $164^{\circ}-188^{\circ}$ of rotation (assuming 00 in the highest position of a pedal and direction of rotation ensuring the drive),

- at position U2 taken by a cyclist (height of a saddle "correct", foot "incorrectly"), reflective effect given by the element mounted on the bicycle pedal - on the one side of a bike - observed within the range of $46 \%$ of full crank rotation; more powerful reflective effect was emitted within the range of $8 \%$ of full crank rotation, which corresponded to its angular position within the range of $203^{\circ}-233^{\circ}$ of rotation,

- at position U3 taken by a cyclist (height of a saddle "incorrect", foot "correctly"), reflective effect given by the element mounted on the bicycle pedal - on the one side of a bike - observed within the range of $35 \%$ of full crank rotation; more powerful reflective effect was emitted within the range of $7 \%$ of full crank rotation, which corresponded to its angular position within the range of $180^{\circ}-206^{\circ}$ of rotation,

- at position U4 taken by a cyclist (height of a saddle "incorrect", foot "incorrectly"), reflective effect given by the element mounted on the bicycle pedal on the one side of a bike - observed within the range of $33 \%$ of full crank rotation; more powerful reflective effect was emitted within the range of $4 \%$ of full crank rotation, which corresponded to its angular position within the range of $198^{\circ}-213^{\circ}$ of rotation.

Table 2 shows the range of angular position of a plane of the bicycle pedal, where reflective effect was noticeable and intense (stronger).

The values of the angle of deflection of a plane of the bicycle pedal towards the ground - higher than $0^{\circ}-$ corresponding to setting, in which front part of the bicycle pedal - in front of its axis - was raised "to the top". The values of the angle of deflection of a plane of a bicycle pedal towards the ground - lower than $0^{\circ}$ - corresponding to setting, in which front part of the bicycle pedal - in front of its axis was lowered to "the bottom". For the value of $0^{\circ}$ plane of a bicycle pedal was parallel to the ground.

Table 2 The changes of the position of a plane of the bicycle pedal while reflecting reflective effect of specific intensity - depending on the position of a cyclist

\begin{tabular}{|c|c|c|c|}
\hline & & $\begin{array}{l}\text { Lightning from } \\
\text { behind }\end{array}$ & $\begin{array}{c}\text { Lightning from } \\
\text { the front }\end{array}$ \\
\hline \multirow{2}{*}{ U1 } & noticeable & $17^{\circ} \div-26^{\circ}$ & $8^{\circ} \div-20^{\circ}$ \\
\hline & intense & $5^{\circ} \div-22^{\circ}$ & $4^{\circ} \div-9^{\circ}$ \\
\hline \multirow{2}{*}{$\mathrm{U} 2$} & noticeable & $30^{\circ} \div-5^{\circ}$ & $19^{\circ} \div-9^{\circ}$ \\
\hline & intense & $17^{\circ} \div 3^{\circ}$ & $-2^{\circ} \div-8^{\circ}$ \\
\hline \multirow{2}{*}{ U3 } & noticeable & $21^{\circ} \div-28^{\circ}$ & $4^{\circ} \div-26^{\circ}$ \\
\hline & intense & $9^{\circ} \div-28^{\circ}$ & $-6^{\circ} \div-16^{\circ}$ \\
\hline \multirow{2}{*}{ U4 } & noticeable & $26^{\circ} \div-18^{\circ}$ & $20^{\circ} \div-18^{\circ}$ \\
\hline & intense & $15^{\circ} \div-15^{\circ}$ & $0^{\circ} \div-8^{\circ}$ \\
\hline
\end{tabular}




\section{Discussion}

The research showed the impact of the position of a cyclist, direction of lighting the bike and state of cleanliness of the reflective element on the noticing distance and noticing the bike equipped only with reflective elements on the bicycle pedals. While rotating the crank, the reflective elements reflect reflective effect alternately, and the driver of an approaching vehicle can see the effect of "pulsation". The height of the reflective effect is changing. It makes easier notice such cyclist - in comparison with situation, in which reflective effect would be "constant" and at the constant height. The frequency of "pulsation" may be connected with the so-called "cadence", which corresponds to the number of full crank rotations in the unit of time. However, frequency of "pulsation" is not the key parameter that affects recognition by the driver. The longest possible time of reflecting reflective effect and the shortest possible time, when this effect was not reflected seem to be significant. The positions U1 and U3 were the best for the cyclist in a situation, in which the bike was lit from the front. The range of crank rotation, in which the effect was visible (and also the most intense) was the highest for these cases in all analyzed settings. The positions U1 and U2 were the best for a cyclist in a situation, in which the bike was lit from behind. The shortest distance of noticing reflective effect was measured (regardless of direction of lighting) for the position of a cyclist defined as U4.

The impact of direction of lighting of a bike on the possibility of noticing the reflective effect was also observed. The presence of a cyclist on the road (lit from the front) was noticed by the driver from a distance of about $10 \mathrm{~m}$ longer in comparison with situation, in which it was lit from behind. It should be connected with "physical" obstruction of the reflective element by the part of a foot behind the bicycle pedal. The range of crank rotation during visibility of the reflective effect emitted after lighting from the front - regardless of position of the cyclist - was visible within the range of $57-93 \%$ of full rotation. In the case of lighting from behind, the reflective effect was visible within the range of 33-50\% of full range of crank rotation. The cyclist riding in the same direction as the car (lighting from behind) is exposed to greater danger than in case, in which he/she moved in the opposite direction (lighting from the front). The range of crank rotation determined during the research, in which reflective effect was visible allows us to draw another conclusion. In a hypothetical situation, in which cyclist riding a bike equipped only with reflective elements on the bicycle pedals would stop rotate the crank, it may come to a situation, in which, for specific setting of the reflective effect, he/she would not be visible for the driver of an approaching vehicle. In the event of lighting with the use of dipped headlights from behind, reflective effect was reflected within the range not higher than $50 \%$ of full crank rotation (the highest range for the assumption that the saddle is "high", and front part of a foot is put on the bicycle pedal). There is no such risk in case of lighting from the front: reflective effect is emitted regardless of position of the cyclist within the range not higher than $50 \%$ of crank rotation. It means that at least one of the reflective elements directed at an approaching vehicle reflected the light, which would be noticed by the driver of an approaching vehicle.

The impact of state of cleanliness on noticing the reflective effect of the elements on the bicycle pedals was also observed. When it was clean, the distance of noticing after lighting with the use of dipped headlights was not lower than $137 \mathrm{~m}$ - regardless of position of the cyclist. Based on that, it may be said that these elements meet the requirements specified in (Dz.U.2015.305, 2015). Noticing conditions are defined there for lighting with the use of the road lights with the range higher in comparison with the dipped headlights. In the event of dirty elements, distances of noticing the reflective effect after lighting with the use of dipped headlights reduced by about 50-60 m (towards clean elements). The research program did not take lighting of reflective elements with the use of the road lights into account, therefore, fulfillment in this case (or non-fulfillment) of the requirements specified in (Dz.U.2015.305, 2015) can't be confirmed. However, significant impact of the state of cleanliness on the possibility of noticing reflective effect was observed. Based on rational premises, it is doubtful whether the state of cleanliness of these elements was controlled by the cyclists. In the event of potential analysis of the accidents of the cyclists riding the bikes equipped only with the reflective lights on the bicycle pedals, assumed values of noticing distances similar to $150 \mathrm{~m}$ should be supported by thorough analysis of evidence in terms of cleanliness of these elements.

\section{Conclusions}

The reflective elements on the bicycle pedals are not (formally) the element of mandatory additional accessories, required by the regulations. It must be treated as additional accessories (reserve) - they are not applied in the bicycle pedals of some bikes. Such bike accessories may, in some circumstances, enable other road users to notice 
unlit cyclist, however, we may not treat them as reliable. The reflection of light depends on the angle between a plane of the reflective element and source of light. It also depends on whether cyclist moves the crank of the bike during observation by the driver. Autonomous lighting of the bike is the most effective and reliable.

\section{References}

Bartuśka, L., Stopka, O., Lizbetin, J. (2015) "Methodology for Determining the Traffic Volumes on Urban Roads in the Czech Republic", In: Proceedings of 19th International Conference Transport Means 2015, Kaunas, Lithuania, pp. 215-218.

Gogola, M. (2018) "Are the e-bikes more dangerous than traditional bicycles?", In: 2018 XI International Science-Technical Conference Automotive Safety, Casta, Slovakia, pp. 1-4. https://doi.org/10.1109/AUTOSAFE.2018.8373344

Haleem, K., Alluri, P., Gan, A. (2015) "Analyzing pedestrian crash injury severity at signalized and non-signalized locations", Accident Analysis \& Prevention, 81, pp. 14-23. https://doi.org/10.1016/j.aap.2015.04.025

Hiselius, L. W., Svensson, Å. (2017) "E-bike use in Sweden - CO2 effects due to modal change and municipal promotion strategies", Journal of Cleaner Production, 141, pp. 818-824. https://doi.org/10.1016/j.jclepro.2016.09.141

Jurecki, R., Poliak, M., Jaskiewicz, M. (2017a) "Young Adult Drivers: Simulated Behaviour in a Car-following Situation", Promet-Traffic \& Transportation, 29(4), pp. 381-390. https://doi.org/10.7307/ptt.v29i4.2305

Jurecki, R. S., Stańczyk, T. L., Jaśkiewicz, M. J. (2017b) "Driver's reaction time in a simulated, complex road incident", Transport, 32(1), pp. 44-54.

https://doi.org/10.3846/16484142.2014.913535

Langford, B. C., Chen, J., Cherry, C. R. (2015) "Risky riding: Naturalistic methods comparing safety behavior from conventional bicycle riders and electric bike riders", Accident Analysis \& Prevention, 82, pp. 220-226. https://doi.org/10.1016/j.aap.2015.05.016

Levulytė, L., Baranyai, D., Török, A., Sokolovskij, E. (2016) "Bicycles' Role in Road Accidents a Review of Literature", Transport and Telecommunication, 17(2), pp. 122-127. https://doi.org/10.1515/ttj-2016-0011

Lizbetin, J., Bartuśka, L. (2017) "The Influence of Human Factor on Congestion Formation on Urban Roads", Procedia Engineering, 187, pp. 206-211. https://doi.org/10.1016/j.proeng.2017.04.366

Madleňak, R., Hoštáková, D., Madleňakova, L., Drozdziel, P., Török, A. (2018) "The Analysis of the Traffic Signs Visibility During Night Driving", Advances in Science and Technology-Research Journal, 12(2), pp. 71-76.

\section{Acknowledgment}

The project presented in this article is supported by Lublin University of Technology, University of Life Sciences and University of Zilina.

Madleňak, R., Hudák, M. (2016) "The Research of Visual Pollution of Road Infrastructure in Slovakia", In: Mikulski, J. (ed.) Challenge of Transport Telematics, TST 2016, Springer, Cham, Switzerland, pp. $415-425$. https://doi.org/10.1007/978-3-319-49646-7 35

Ministry of Infrastructure of Poland (2015) "Dziennik Ustaw 2015.305 Rozporządzenie ministra infrastruktury z dnia 31 grudnia 2002 r. w sprawie warunków technicznych pojazdów oraz zakresu ich niezbędnego wyposazenia" (Journal of Law 2015.305 Regulation of the minister of infrastructure of 31 December 2002 on the technical conditions of vehicles and the scope of their necessary equipment), Dzienik Ustaw Rzeczypospolitej Polskiej, Warszawa, Poland [online] Available at: https://www.gddkia.gov.pl/userfiles/ articles/w/warunki-techniczne-pojazdow_11617//Warunki\%20techniczne\%20pojazdów.pdf [Accessed: 10 February 2019] (in Polish)

Schepers, J. P, Wolt, K. K. (2012) "Single-Bicycle Crash Types and Characteristics", Cycling Research International, 2, pp. 119-135.

Skrúcaný, T., Šarkan, B., Figlus, T., Synák, F., Vrábel, J. (2017) "Measuring of noise emitted by moving vehicles", In: Dynamics of Civil Engineering and Transport Structures and Wind Engineering (DYN-WIND), MATEC Web of Conferences, 107, Article number: 00072. https://doi.org/10.1051/matecconf/201710700072

Tarkowski, S. (2017) "Badanie rozkładu plamy świateł mijania współczesnych pojazdów" (Study of the distribution of dipped-beam spotlights of modern vehicles), Autobusy, 12, pp. 1345-1350. (in Polish)

Tarkowski, S., Bieniek, P., Górski, K. (2017) "Wpływ jakości źródeł światła i stanu technicznego reflektorów na rozkład plamy świateł mijania pojazdów samochodowych" (Influence of the quality of light sources and the technical condition of the headlamps on the distribution of the carıs dipped-beam spots), Autobusy, 6, pp. 434 439. (in Polish)

Weber, T., Scaramuzza, G., Schmitt, K .U. (2014) "Evaluation of e-bike accidents in Switzerland", Accident Analysis \& Prevention, 73, pp. $47-52$.

https://doi.org/10.1016/j.aap.2014.07.020 